\title{
MODELO HIDROGEOLÓGICO CONCEPTUAL DEL ACUÍFERO NIMBOYORES, GUANACASTE, COSTA RICA
}

\author{
HYDROGEOLOGICAL CONCEPTUAL MODEL NIMBOYORES AQUIFER, \\ GUANACASTE, COSTA RICA
}

\author{
Mario A. García ${ }^{1 *} \&$ Federico Arellano² \\ ${ }^{1}$ Programa Posgrado Centroamericano en Geología, \\ Apdo. 2014-2060 UCR, San José, Costa Rica \\ ${ }^{2}$ Hidrogeotecnia S.A. \\ *Autor para contacto: mario3garcia@gmail.com.
}

(Recibido: 9/02/2012 ; aceptado: 17/12/2012)

\begin{abstract}
The Nimboyores aquifer, located in the province of Guanacaste (Costa Rica) has been defined in this work as an unconfined aquifer, it is composed of three layers: the deepest one is a thick colluvium, the intermediate is a thin colluvium and at the top there is a sandy clay soil. The basement depth varies between 30 and $45 \mathrm{~m}$. This model was obtained by correlating the results of 7 vertical electrical soundings with 50 wells with lithological information provided by the SENARA. The hydraulic conductivities of such layers are respectively 300,60 and $10 \mathrm{~m} / \mathrm{d}$. The total recharge to the aquifer is of $1211 \mathrm{l} / \mathrm{s}$, obtained from the water balance. Based on the record levels in 14 wells collected during 7 years monitored by SENARA, static levels were established for the driest month recorded. The conceptual model improved the understanding of the groundwater flow and the influence of the geological setting.

Keywords: Aquifer, model, Nimboyores, static level, water balance, differential gauging, wells.

RESUMEN: El acuífero de Nimboyores, ubicado en la provincia de Guanacaste (Costa Rica) ha sido definido en este trabajo como un acuífero libre, está compuesto por tres capas: un coluvio grueso en la parte inferior, seguido de un coluvio fino y en la parte superior suelo areno- arcilloso. La profundidad del basamento varía entre los 30 y $45 \mathrm{~m}$. Este modelo fue obtenido mediante la correlación de los resultados de 7 sondeos eléctricos verticales con 50 pozos con información litológica facilitados por el SENARA. Las conductividades hidráulicas de dichas capas son, respectivamente, 300, 60 y $10 \mathrm{~m} / \mathrm{d}$. La recarga total al acuífero es de 1211 1/s, obtenida a partir del balance hídrico. Con base en el registro de niveles en 14 pozos obtenidos durante 7 años monitoreados por el SENARA, se establecieron los niveles estáticos para el mes de mayor sequía registrada. El modelo conceptual mejora el entendimiento del flujo de agua subterránea y la influencia de las condiciones geológicas.

Palabras clave: Acuífero, modelo, Nimboyores, nivel estático, balance hídrico, aforo diferencial, pozos.
\end{abstract}




\section{INTRODUCCIÓN}

El Acuífero Nimboyores está localizado en la zona del pacífico norte de Costa Rica, en la provincia de Guanacaste (Fig.1), y constituye la fuente fundamental de suministro de agua para las poblaciones de Cartagena, Tempate y Lorena. El fenómeno de déficit de abastecimiento aumenta por los períodos de sequía, predominantes en los meses comprendidos entre diciembre y abril, de acuerdo al análisis de los datos históricos de precipitación suministrados por el Instituto Meteorológico Nacional (IMN). Este comportamiento climático es característico de esta franja costera.

De acuerdo con la información de la base de datos del Servicio Nacional de Aguas Subterráneas Riego y Avenamiento (SENARA), en los informes de perforación de pozos del área de estudio, se muestra que la profundidad del basamento oscila entre 30 y $45 \mathrm{~m}$, y es subyacido por una serie de capas de espesor variable conformadas por sedimentos de coluvios, arena y gravas, seguido de coluvios con arenas, arcillas y limos, gravas medias con contenidos de arena y arcilla, para aflorar en algunas zonas en arenas $y$ en otras en arcillas de color gris verdoso con algún contenido de arena.

El estudio del acuífero Nimboyores cobra importancia en el año 2003, debido a la construcción de un sistema de acueducto que abastecería a un desarrollo hotelero en una zona costera de Brasilito. Este sistema estaría compuesto de una batería de pozos que explotarían a gran escala el acuífero Nimboyores para abastecer al complejo turístico (Segnini, 2007). Esta situación causó malestar en algunas comunidades vecinas y como consecuencia de la controversia a nivel nacional (Araya, 2008) y las denuncias a nivel internacional (Tribunal Latinoamericano del agua, 2004), se han realizado varios estudios, principalmente hidrogeológicos, para evaluar el potencial del acuífero, como por ejemplo el realizado por Ramos (2001). Posteriormente se continuó con el monitoreo de las aguas subterráneas desde el año 2003 en los acuíferos en la parte alta de la subcuenca del río Nimboyores (Pérez, 2004), y finalmente se realizó el diagnóstico del potencial de

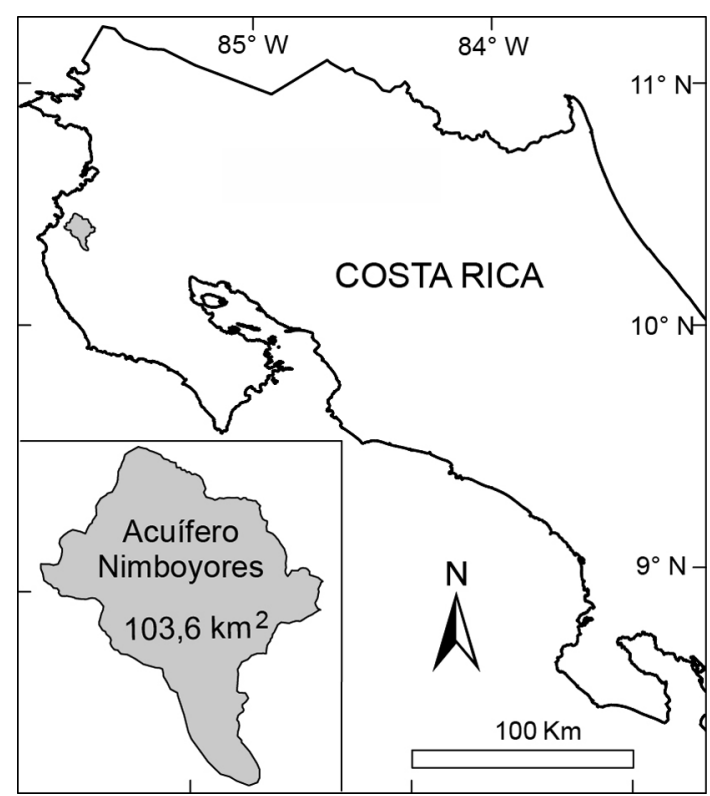

Fig. 1: Ubicación geográfica del acuífero Nimboyores (área sombreada en gris). Coordenadas geográficas, elipsoide WGS84.

explotación y rendimiento seguro del acuífero en la parte alta de la subcuenca del río Nimboyores (Agudelo, 2005). También se realizaron esfuerzos para buscar herramientas que permitieran la toma de decisiones en el manejo del recurso hídrico y se planteó el plan maestro integral de la microcuenca del río Nimboyores y su área de influencia (Burgos, 2004).

Debido a los conflictos generados por los distintos usos del recurso hídrico en la zona, surge la necesidad de conocer la dinámica del acuífero Nimboyores a través de un modelo numérico, el cual solo puede ser llevado a cabo si se establece claramente un modelo hidrogeológico conceptual y que constituye el tema que se desarrolla en este artículo, para lo cual se consideraron estudios de importancia, tales como los realizados por Ramos (2001), Burgos (2004) y Agudelo (2005), de los cuales se recopiló información de pruebas de infiltración, pruebas de bombeo, monitoreo de niveles estáticos entre otras exploraciones de campo que sirvieron para las consolidación del modelo numérico; se incluyeron además aforos diferenciales en ríos y los caudales de explotación de pozos. De esta manera con la información generada, los usuarios del 
acuífero e instituciones vinculadas podrán tomar acciones para elaborar una mejor planificación del recurso hídrico y su apropiada protección.

\section{METODOLOGÍA}

Se recopiló y analizó la información existente referente a la geología, clima, hidrogeología e hidrología, incluyendo además descripción litológica de 72 pozos registrados en la base de datos del SENARA, ubicación geográfica, profundidad de los niveles estáticos, características del acuífero y parámetros hidráulicos obtenidos a partir de pruebas de bombeo recopiladas por el SENARA. El trabajo de campo consistió en la realización de campañas para elaborar pruebas de infiltración, sondeos eléctricos verticales (SEV) y medición de niveles estáticos durante dos años, los cuales se integraron con los registros de 7 años de datos recopilados a partir de trabajos anteriores, además de datos de precipitación facilitados por el Instituto Meteorológico Nacional (IMN).

El modelo de elevación del terreno fue generado por medio de la información facilitada por el Programa de Regularización de Catastro y Registro (PRCR) del 2007, con curvas de nivel cada $5 \mathrm{~m}$. Asimismo el uso del suelo fue determinado con el análisis de fotografías aéreas tomadas en el año 2007 a escala 1:25 000 generadas por el PRCR, esta información fue corroborada en campo en el año 2011, donde se observo que las zonas clasificadas con los distintos usos del suelo siguen siendo las mismas a las realizadas con las fotografías aéreas tomadas en el año 2007. La capacidad de infiltración del suelo se estableció mediante ensayos tipo anillos concéntricos o método de Müntz (Custodio \& Llamas, 1983) realizados por Acueductos y Alcantarillados (AyA), el Centro Agronómico Tropical de Investigación y Enseñanza (CATIE) y el SENARA, descritas en las publicaciones de por Ramos (2001), Burgos (2004) y Agudelo (2005) respectivamente, el cual consiste en dos superficies cilíndricas abiertas en sus bases y unidas entre sí para mantenerse concéntricas al hincarlas parcialmente en el terreno a una profundidad de unos $10 \mathrm{~cm}$. Posteriormente se aplica una carga de agua constante al suelo, añadiéndole un volumen conocido de agua entre los dos cilindros. La prueba de infiltración consiste en medir los tiempos que tardan en infiltrarse el agua, calculándose de esta manera la capacidad de infiltración.

Se utilizó la metodología de Schosinsky (2006) para el estudio del balance de suelos utilizado, el cual se basa en el principio de la conservación de la materia. O sea, el agua que entra a un suelo, es igual al agua que se almacena en el suelo, más el agua que sale de él. Las entradas son debidas a la infiltración del agua hacia el suelo, y las salidas se deben a la evapotranspiración de las plantas, más la descarga de los acuíferos. $\mathrm{La}$ recarga al acuífero se determina conociendo en primer lugar, la fracción de lluvia que es interceptada por el follaje. En segundo lugar, se requiere conocer la infiltración del agua de lluvia hacia el suelo, generada por la precipitación que llega a su superficie y en tercer lugar, se debe realizar un balance de suelos, que nos permita estimar el agua que drena del suelo hacia el acuífero (Cuadro 1).

\section{GEOLOGÍA}

La geología del área de estudio está comprendida por las siguientes formaciones geológicas:

\section{Complejo de Nicoya}

Muchos autores describen las rocas del Complejo, entre estos Denyer \& Gazel (2009) citan la ubicación de las rocas del Complejo en varias zonas del país, Santa Elena, Península de Nicoya, Herradura y Quepos, así como en Osa y Burica. La describen compuesta por una agrupación de litologías ígneas y sedimentarias del Cretácico, donde sobresalen basaltos, basalto-aglomerados, doleritas, gabros, dioritas y pedernales.

Estas rocas son sobreyacidas discordantemente por las rocas de la Formación Sabana Grande y se le atribuye una edad según Kuypers (1979) generados desde el Berriasiano hasta el Campaniano, esto debido a:

- Rocas pre-Campanianas: formadas por rocas de origen ofiolítico fuertemente plegadas.. 
Cuadro 1

Descripción de la metodología

\begin{tabular}{|c|c|c|}
\hline $\begin{array}{l}\text { Recolección } \\
\text { información }\end{array}$ & Análisis de información & Resultados \\
\hline Geología & Exploración de 2 campañas geológicas (Fuente: Investigación) & \multirow{2}{*}{$\begin{array}{l}\text { Dominio de la cuenca y delimit- } \\
\text { ación del acuífero en planta }\end{array}$} \\
\hline Geomorfología & Análisis del modelo digital del terreno (Fuente: PRCR, 2007) & \\
\hline Estratigrafía & Estudio de 72 pozos con litología (Fuente: SENARA) & \multirow{2}{*}{$\begin{array}{l}\text { Profundidad del basamento y espe- } \\
\text { sor del acuífero }\end{array}$} \\
\hline $\begin{array}{c}\text { Prospecciones } \\
\text { geofísicas }\end{array}$ & Análisis de 7 SEV (Fuente: Investigación) & \\
\hline Monitoreo de pozos & Registro niveles estáticos de 7 años (Fuente: SENARA) & \multirow{3}{*}{$\begin{array}{l}\text { Propiedades Hidrogeológicas del } \\
\text { acuífero }\end{array}$} \\
\hline Pruebas de bombeo & Análisis de 7 pruebas de bombeo (Fuente: SENARA) & \\
\hline $\begin{array}{l}\text { Aforo diferencial } \\
\quad \text { en ríos }\end{array}$ & $\begin{array}{l}\text { Aforo de caudales diferenciales en ríos(Fuente: AyA SENARA- } \\
\text { Investigación) }\end{array}$ & \\
\hline Humedad & 18 muestras CC y PM (Fuente: Investigación) & \multirow{4}{*}{$\begin{array}{l}\text { Balance hídrico de suelos (Scho- } \\
\text { sinsky, 2006) }\end{array}$} \\
\hline Infiltración & $\begin{array}{l}21 \text { Pruebas de Infiltración (Fuente: AyA-CATIE-SENARA- } \\
\text { Investigación) }\end{array}$ & \\
\hline Uso del suelo & Clasificación del suelo (Fuente: PRCR, 2007 - Investigación) & \\
\hline Clima & Precipitación, temperatura y brillo solar (Fuente: IMN) & \\
\hline
\end{tabular}

- Campaniano: asociaciones ígneas desde andesitas hasta basaltos, siendo estos últimos más abundantes.

Kuypers (1979) describe dentro del complejo dos unidades: una inferior la Unidad Matapalo, que consiste de aproximadamente $150 \mathrm{~m}$ de basaltos que son sobreyacidos por al menos $40 \mathrm{~m}$ de radiolaritasLa edad de esta unidad es Jurásico Superior al Cretácico Superior (Baumgartner, 1984). Kuypers (1979) también describe la Unidad Esperanza compuesta de basaltos y diabasa ofítica con gabros y diques plagiograníticos y localmente intercalaciones radiolaríticas en la parte superior de la unidad.

Otros autores como Sinton et al. (1997), Baumgartner \& Denyer (2006), Denyer \& Baumgartner (2006), Denyer et al. (2006), Baumgartner (1984) y Denyer \& Gazel (2009) describen las rocas del complejo ubicadas en la Península de Nicoya, de composición basáltica tanto masivos como pillow con diques y brechas, gabros, doleritas y dioritas así como sucesiones radiolaríticas. La edad atribuida a estas rocas es del Cretácico.

En la zona de estudio se observaron los basaltos aflorando en toda la parte alta de la cuenca, la cual presenta una forma en herradura, formando la divisoria de aguas de la cuenca hidrológica del río Nimboyores. En la zona estos basaltos se presentan meteorizados de coloración gris clara, así como fracturados. Mientras que los basaltos sanos, presentan coloración gris oscuro, de textura afanítica y con fracturas y microfracturas rellenas de calcita o sílice.

En lo que respecta a las radiolaritas, estas se encuentran aflorando en las partes bajas de la cuenca en el sector SE. Estas rocas se presentan básicamente en lomas aisladas y cerros relictos, en macizos rocosos fracturados de mala a muy mala calidad, de coloración rojiza y notablemente afectado en algunos sectores por plegamiento.

\section{Formación Sabana Grande}

Estas rocas afloran hacia el sector sur de la cuenca en el cerro Palizada y pequeños cerros relictos que no sobrepasan los $40 \mathrm{~m}$ de altura con relación a la superficie más baja del terreno. Denyer \& Arias (1993) describen tres tipos de litologías: lutitas calcáreas, lutitas silíceas y areniscas finas calcáreas, además Denyer et al. (2005) describe que esta se encuentra compuesta por sedimentos silíceos y carbonatados de origen pelágico, hemi- 
pelágico y turbidítico. Estas rocas se presentan macroscópicamente poco alteradas, su coloración es gris claro a gris crema, presentan laminación paralela y micro fracturas rellenas de calcita, forman un macizo rocoso con paquetes de estratos de 5 a $10 \mathrm{~cm}$ de espesor, es común observar fracturación en todas las direcciones lo que les da un comportamiento deleznable.

Esta se encuentra sobreyaciendo discordantemente al Complejo de Nicoya. Baumgartner (1984) le asigna una edad Campaniano inferior, mientras que Denyer et al. (2005) le atribuye una posible edad de Cenomaniano-Coniaciano.

\section{Depósitos Coluvio-Aluviales}

Esta unidad fue descrita y diferenciada directamente en el campo por el geólogo Allan Alan en octubre del 2009 como colaboración a la investigación. El depósito aflora en toda la parte baja de la cuenca Nimboyores y es el resultado de la erosión y depositación del sistema fluvial que la drena. Con base en las perforaciones de pozos y los SEV realizados en este trabajo, el espesor de esta unidad no sobrepasa los $45 \mathrm{~m}$ en su parte más profunda. Las perforaciones hidrogeológicas que se encuentran cerca de las partes altas de la cuenca, presentan una columna estratigráfica representada por: un coluvio grueso en su parte inferior que varía su espesor entre los 10 a $15 \mathrm{~m}$, seguido de intercalaciones de arenas finas y capas arcillo limosas que coronan el depósito. En superficie se encuentran pocos afloramientos de donde se pueden describir estos materiales. Uno de ellos corresponde al punto ubicado en el sector este de la cuenca en las coordenadas geográficas 353672 E - $264305 \mathrm{~N}$, en este sitio se observó un deposito coluvio aluvial fino con gradación inversa como se muestra en la figura 2. En la parte superior del depósito aparece un suelo limoso de $50 \mathrm{~cm}$ de espesor, seguido a profundidad por $80 \mathrm{~cm}$ de gravas finas las cuales poseen clastos cuyos diámetros varían entre los 2 a $0,5 \mathrm{~cm}$. Los clastos son sub-redondeados a sub-angulares y se encuentran en contacto flotante dentro de una matriz limo-arcillosa color rojiza que corresponde a un $40 \%$ del estrato. Posteriormente por debajo de la segunda capa

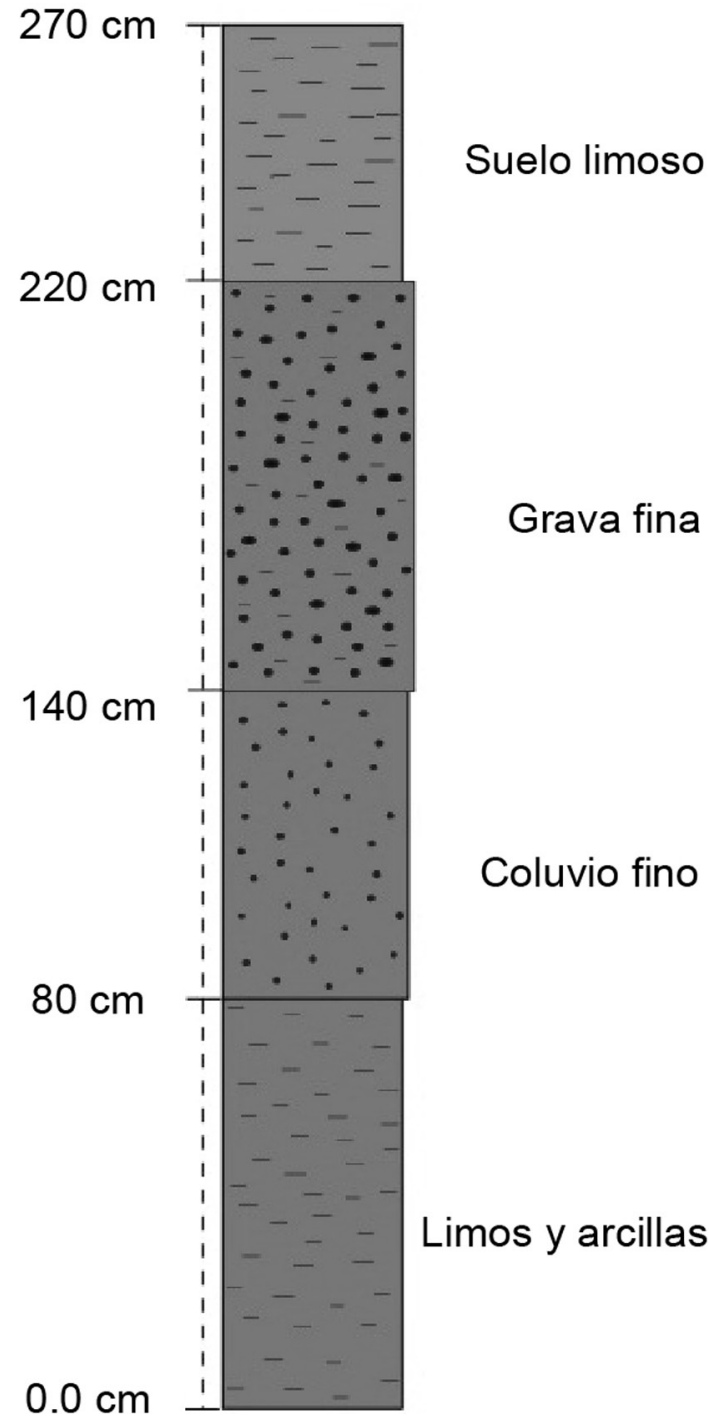

Fig. 2: Columna esquemática del corte coluvio-aluvional.

existen $60 \mathrm{~cm}$ de un coluvio más fino, donde los clastos no sobrepasan los $0,5 \mathrm{~cm}$ de diámetro y el porcentaje de matriz aumenta a $60 \%$ y la coloración es rojiza. Los últimos $80 \mathrm{~cm}$ de la columna están representados por la matriz rojiza de carácter limo arcilloso.

Es importante destacar que estos depósitos varían en su coloración y en el grado de meteorización de los clastos dependiendo del sector de la cuenca donde se ubiquen, ya que por ejemplo hacia el sector norte, en la coordenada 348349 E - $268269 \mathrm{~N}$, afloran depósitos coluvio aluviales de coloración 
gris claro y con granulometrías más gruesas y clastos basálticos, en estado menos meteorizados con relación al sector sureste de la cuenca.

A lo largo de toda la cuenca y principalmente en el centro de la misma, existe una capa de arcillas de color grisáceo que presenta espesores de entre los 0,5 a $1,5 \mathrm{~m}$ que cubre la secuencia sedimentaria. Debido a la posición geográfica y a las características de las arcillas antes mencionadas, hace suponer un origen lacustre que corona la estratigrafía. La edad de esta unidad es Cuaternario hasta el presente. Hidrogeológicamente, los materiales del Complejo de Nicoya constituyen el basamento de la zona y se identificó con base en los datos de perforación a unos 35 m.b.n.s en las partes bajas y planas de la cuenca. Con base en el modelo hidrogeológico planteado, estos basaltos corresponden con las barreras laterales e inferior del acuífero coluvio aluvial de la cuenca Nimboyores, pudiendo representar zonas permeables con almacenamiento de agua subterránea en aquellos sectores que se encuentren altamente fracturados, por lo que no se descarta el aporte lateral de agua hacia el acuífero Nimboyores (Zúñiga, 2005). En lo que respecta a la Formación Sabana Grande esta presenta zonas permeables con almacenamiento de agua subterránea y recarga en aquellos sectores donde se encuentra altamente fracturada. La figura 3 muestra la geología del área de estudio, obtenida a partir del estudio de Denyer \& Arias (1993).

\section{CAMPAÑA GEOFÍSICA}

Con el objetivo de recabar información hidrogeológica en zonas donde no existen perforaciones, se llevó a cabo una campaña geofísica compuesta por 7 sondeos eléctricos verticales (SEV), utilizando el dispositivo geoeléctrico de Schlumberger, con un $\mathrm{AB} / 2$ variable de 1 a $50 \mathrm{~m}$, con el fin de poder explorar hasta una profundidad máxima de $150 \mathrm{~m}$.

La ubicación de los SEV (Cuadro 2) se eligió con base en objetivos hidrogeológicos así como

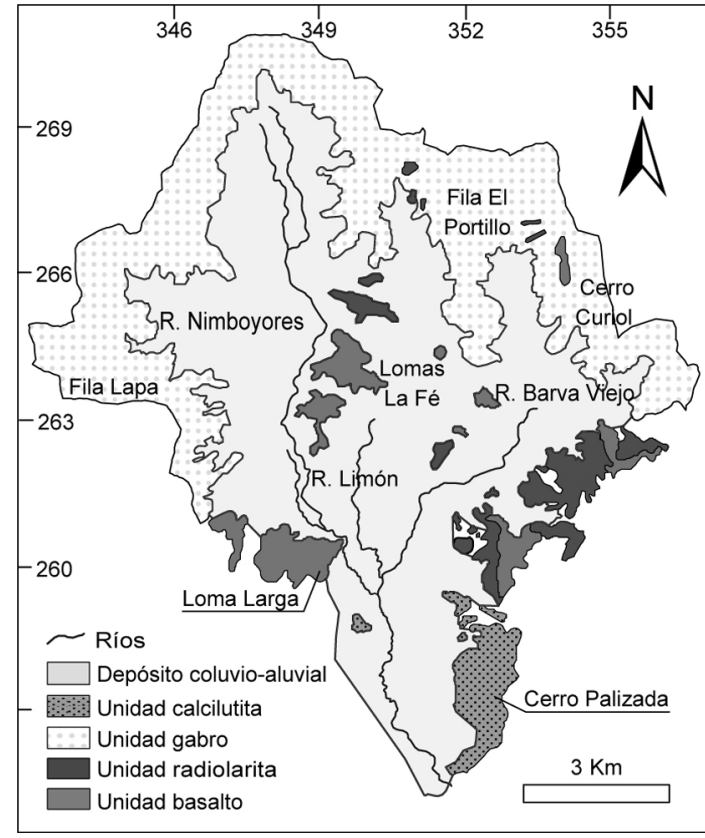

Fig. 3: Geología de la zona de estudio. Basado en mapa geológico Denyer \& Arias (1993).

las facilidades y limitaciones logísticas (topografía, accesos, entre otros). Por la separación de los sondeos no fue posible hacer correlaciones, por lo que se analiza cada sondeo por separado (Cuadro 3). Asimismo la presencia de importantes espesores de capas de arcillas (a nivel superficial) en la unidad coluvio aluvial Nimboyores, dificultan por interferencia la diferenciación a profundidad de capas resistivas dentro del coluvión mismo.

Con base en estos resultados se obtiene que hacia el sector noroeste y este de la cuenca, la Unidad coluvio-aluvial Nimboyores presenta capas espesas de $5 \mathrm{~m}$ de espesor compuesto de materiales arcillosos muy conductores que contrastan con los materiales resistivos del basamento. Esto representa una limitante para determinar el espesor real del acuífero en este sector. Por otra parte, los SEV 1, 2 y 6, permiten ver con claridad el espesor aparente de los materiales saturados de la Unidad coluvioaluvial Nimboyores, los cuales presentan espesores entre los 15 a $47 \mathrm{~m}$ aproximadamente. 
Cuadro 2

Coordenadas de ubicación de los sondeos en coordenadas Lambert Costa Rica Norte

\begin{tabular}{ccc}
\hline SEV & Este $(\mathrm{m})$ & Norte $(\mathrm{m})$ \\
\hline SEV-1 & 347793 & 260590 \\
SEV-2 & 346171 & 264319 \\
SEV-3 & 352728 & 262698 \\
SEV-4 & 353655 & 264452 \\
SEV-5 & 347103 & 264736 \\
SEV-6 & 349705 & 266135 \\
SEV-7 & 349948 & 258549 \\
\hline
\end{tabular}

\section{DESARROLLO DEL MODELO CONCEPTUAL}

El modelo conceptual fue elaborado a partir de las siguientes etapas:

\section{Perfiles geológicos}

Con base en la distribución de los pozos con información litológica y los SEV en el área de estudio se elaboraron dos perfiles geológicos. En la figura 4 se muestra el basamento del acuífero compuesto por las formaciones geológicas antes descrita, y sobre el, yace los depósitos coluvio aluviales que componen el acuífero.

\section{Perfil Geológico A-Á}

Permite visualizar la secuencia sedimentaria longitudinal a la cuenca. El perfil nos ayuda a definir la estructura del basamento, permitiendo conocer su profundidad donde existe información. Cabe resaltar que para efectos de la modelación numérica adicionalmente se realizó con la información existente, una malla tridimensional que representa aproximadamente el basamento, este conforma el piso del acuífero y los cerros que sobresalen en medio de él. Los depósitos coluvio aluviales que conforman el acuífero llenan la cuenca formando una planicie que rodea y envuelve a los cerros, en el sector norte la depositación de los coluvios gruesos ocurre cercano al pie de monte (Pozo BE-2) de igual manera que ocurre en el sector medio a bajo de la cuenca (Pozo BE369), estos son puntos que muestran una mayor conductividad hidráulica y donde predominan materiales compuestos de arena fina a gruesa con conteniendo de gravas y cantos rodados medianos a grandes; en dichas zonas actualmente existe mayor explotación gracias a la ocurrencia del agua subterránea. Los coluvios finos provistos de arena fina con gravas, arcilla, cantos rodados medianos a pequeños componen el resto del acuífero, y se depositan en el valle constituyendo una pendiente en constante descenso, lo que refleja un gradiente hidráulico en la misma dirección, en el sector sur a la salida del acuífero, los coluvios terminan nivelándose conformando una planicie de inundación que es utilizada para cultivos de arroz (Pozos DI-170,199 y 200). En la capa final, el suelo esta constituido por intercalaciones de arcillas con arenas finas culminando con el top soil (material de cultivo); dicha configuración permite la ocurrencia de un acuífero libre con muy poca posibilidad de confinamiento.

\section{Perfil Geológico B-B'}

Ubicado en la parte media a baja del acuífero en sentido oeste-este alineado al trazo por donde desciende el rio Barba viejo. En la margen este se encuentra la depositación de coluvios gruesos localizado al pie de monte, claramente identificado por los pozos BE-463 y BE-480 localizados en el poblado de Cartagena donde se cubre la mayor demanda de explotación del acuífero. Los coluvios finos viajan del pozo BE-164 en una pendiente de continuo descenso hasta el pozo BE-369 en esta franja predominan los coluvios finos que genera el gradiente hidráulico que baja en dirección al rio Barba viejo hasta la intersección de los ríos Limón y Nimboyores, existe una depositación de coluvios gruesos entre las 
Cuadro 3

Resumen de resultados de sondeos eléctricos verticales

\begin{tabular}{|c|c|c|c|c|}
\hline Sondeo & Horizonte & $\begin{array}{l}\text { Espesor } \\
(\mathrm{m})\end{array}$ & Litología & $\begin{array}{c}\text { Resistividad } \\
(\mathrm{Ohm} * \mathrm{~m})\end{array}$ \\
\hline \multirow[t]{3}{*}{$\mathrm{SEV} \mathrm{N}^{\circ} 1$} & $\mathrm{H} 1$ & 1 & Suelos arcillosos & 40,7 \\
\hline & $\mathrm{H} 2$ & 45 & Unidad coluvio aluvial Nimboyores & 21,4 a 25,7 \\
\hline & $\mathrm{H} 3$ & 43 a ? & Basamento & 4187 \\
\hline \multirow[t]{3}{*}{$\mathrm{SEV} \mathrm{N}^{\circ} 2$} & $\mathrm{H} 1$ & 0,5 & Suelos arcillosos & 15,3 \\
\hline & $\mathrm{H} 2$ & 13,3 & Unidad coluvio aluvial Nimboyores & 23,3 \\
\hline & $\mathrm{H} 3$ & $14 \mathrm{a} ?$ & Complejo Nicoya fracturado y saturado superficialmente & 68,5 \\
\hline \multirow[t]{3}{*}{$\mathrm{SEV} \mathrm{N} 3$} & $\mathrm{H} 1-\mathrm{H} 2$ & 3,37 & Material muy arcilloso & 4,1 a 54,4 \\
\hline & $\mathrm{H} 3$ & 15 & $\begin{array}{l}\text { Basalto del Complejo de Nicoya. Este contraste de resistividades no per- } \\
\text { mite ver con el espesor de la zona saturada de la unidad coluvio aluvial }\end{array}$ & 2651 \\
\hline & $\mathrm{H} 4$ & $?$ & & \\
\hline \multirow[t]{3}{*}{$\mathrm{SEV} \mathrm{N}{ }^{\circ} 4$} & H1 & 0,63 & Suelos limo arcilloso. & 5,49 \\
\hline & $\mathrm{H} 2-\mathrm{H} 3$ & 5,60 & Material muy arcilloso & 24,3 a 64,3 \\
\hline & $\mathrm{H} 4$ & $?$ & Basalto del Complejo de Nicoya & 1330 \\
\hline \multirow[t]{3}{*}{$\mathrm{SEV} \mathrm{N}^{\circ} 5$} & $\mathrm{H} 1$ & 0,54 & Suelos limo arcilloso & 118 \\
\hline & $\mathrm{H} 2$ & 2,53 & Material muy arcilloso & 7,44 \\
\hline & H3 & $?$ & Basamento & \\
\hline \multirow[t]{2}{*}{$\mathrm{SEV} \mathrm{N}^{\circ} 6$} & H1 & 15,7 & Unidad coluvio aluvial saturada & 39,2 \\
\hline & $\mathrm{H} 2$ & $16 \mathrm{a} ?$ & Basamento & 18681 \\
\hline \multirow[t]{3}{*}{$\mathrm{SEV} \mathrm{N} \mathrm{N}^{\circ}$} & $\mathrm{H} 1-\mathrm{H} 2$ & 0,5 & Suelo arcillo limoso & 553 a 1511 \\
\hline & $\mathrm{H} 3-\mathrm{H} 4$ & 7 & Material coluvio aluvial sin saturación & 1511 a 7522 \\
\hline & H5 & $?$ & Material muy resistivo & 83000 \\
\hline
\end{tabular}

márgenes del rio Barba viejo y limón donde aún en poca de mayor sequia estos ríos conservan agua en su cauce, por lo que es la zona mas húmeda de la cuenca. En la figura 5 se evidencia la profundidad del basamento rocoso en la parte baja de la cuenca la cual se encuentra entre $35 \mathrm{y}$ $50 \mathrm{~m}$ de profundidad.

\section{Flujo del agua subterránea}

El mapa de curvas isofreáticas puede visualizarse para cualquier época, sin embargo fue elegida la información de 14 pozos que fueron monitoreados el día 27 de abril del 2010 tras 5 meses de sequía registrada, día en el cual se realizaron paralelamente aforos diferenciales en los ríos y además se midió la diferencia de nivel de la lámina de agua del cauce respecto a la superficie, por otra parte se analizaron tramos secos y tramos con agua, parámetros que fueron útiles para definir un punto de calibración en un modelo numérico realizado, que representa el componente final de la investigación realizada, y que no hace parte del contenido del presente artículo. Por otra parte en la figura 6 se observa los resultados de las líneas equipotenciales tras una calibración exhaustiva con el programa de modelación numérica Visual Modflow Premium 2010, donde se consideraron los parámetros hidrodinámicos del acuífero, y demás las barreras negativas o celdas de no flujo o inactivas que componen los afloramientos del complejo de Nicoya. Las variaciones de los niveles estáticos en la extensión de la cuenca representan un comportamiento particular, los valores indicados en los puntos muestran la altura 


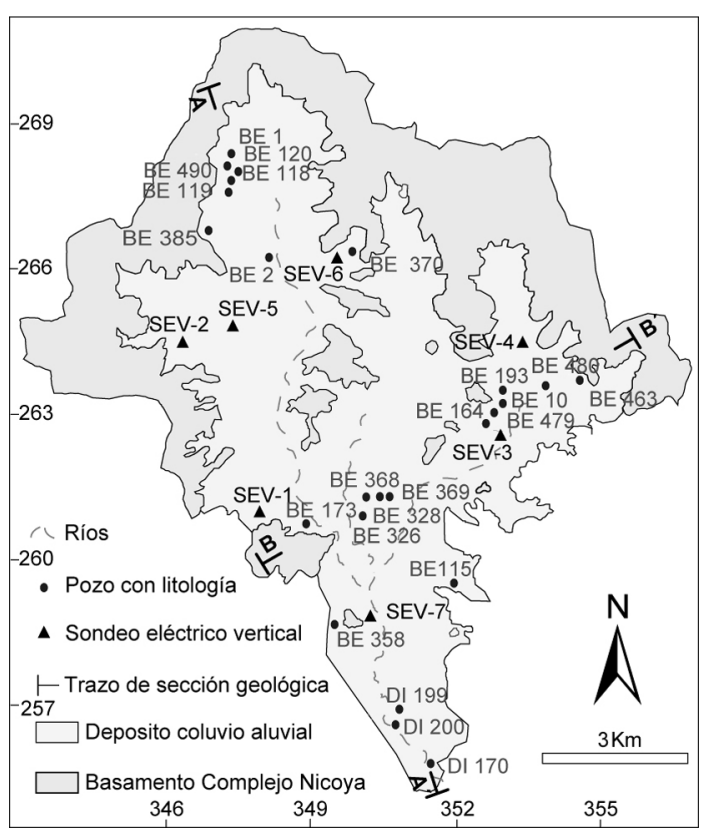

Fig. 4: Ubicación de los perfiles geológicos, ubicación de los pozos y sondeos eléctricos verticales.

del nivel estático respecto al nivel del mar. Al lado sur no existe información de pozos monitoreados, pero según la extrapolación realizada por medio del software de modelación Visual Modflow Premium 2010, se muestra un comportamiento que desborda a la planicie de inundación donde predominan los cultivos de arroz.

\section{Variación temporal de los niveles estáticos}

La figura 7 muestra la variación temporal de los niveles estáticos durante el periodo de septiembre del 2003 a mayo 2011, calculado a partir de la información de los 14 pozos de observación con registro continuo. Se puede observar que el periodo de recarga para el acuífero inicia en mayo y termina en noviembre.

\section{Propiedades hidrodinámicas del acuífero}

El SENARA dentro de su base de datos cuenta con 7 pruebas de bombeo a caudal constante realizadas en la zona, esta información junto a otras 6 pruebas realizadas en el transcurso de la investigación permitieron determinar los valores de conductividad y transmisividad, estableciendo en total 13 puntos de exploración (Fig. 8). Se utilizó el método de Theis Jacob Corregido el cual fue complementado con el análisis de los descensos, Se obtuvo un rango de valores de conductividad hidráulica (K), entre los 1,24 y 69,7 m/d, así como una transmisividad (T) de 32,2 a $566 \mathrm{~m}^{2} /$ d. Esto permite calificar de medianas a buenas las características hidráulicas del acuífero. En las figuras 9, 10 y 11, muestra la curva representativa para las pruebas de bombeo P5, P6 y P11 respectivamente.

En la figura 9 se muestra el análisis y la interpretación de la curva de recuperación de ascensos residuales por el método de Theis Jacob Corregida en el pozo de prueba P5 después de un bombeo a caudal constante por 12 horas, estimado, así mismo en la figuras 10 y 11 se muestra el método Newman y Theis Jacob Corregida, para los pozos de prueba P6 y P11 respectivamente. En el análisis realizado a la prueba P5 se encontró una transmisividad de $32,2 \mathrm{~m}^{2} /$ día y una conductividad hidráulica de $11 \mathrm{~m} /$ día, así mismo la prueba P6 dio como resultado una transmisividad de 57,8 $\mathrm{m}^{2} /$ día y una conductividad hidráulica de $12,4 \mathrm{~m} /$ día, la prueba P11 suministró resultado más altos con una transmisividad de $80,1 \mathrm{~m}^{2} /$ día y una conductividad hidráulica de 15,4 m/día.

\section{Aforo diferencial en ríos}

La exploración de los ríos Nimboyores, Barba Viejo y Limón realizadas en la presente investigación fue realizada el día 27 de abril del 2010 con la cooperación del SENARA. Las condiciones de sequía permitieron la compresión del flujo del agua subterránea en el acuífero. En la figura 5 se identifican tramos secos y tramos con agua en el recorrido del río Nimboyores, visualizándolo que pone en evidencia un flujo intermitente desde la naciente hasta la salida de la cuenca. La altura topográfica de las nacientes de los ríos Nimboyores y Limón coinciden con el valor de las curvas equipotenciales que pasan por ese punto, lo que indica que las nacientes 

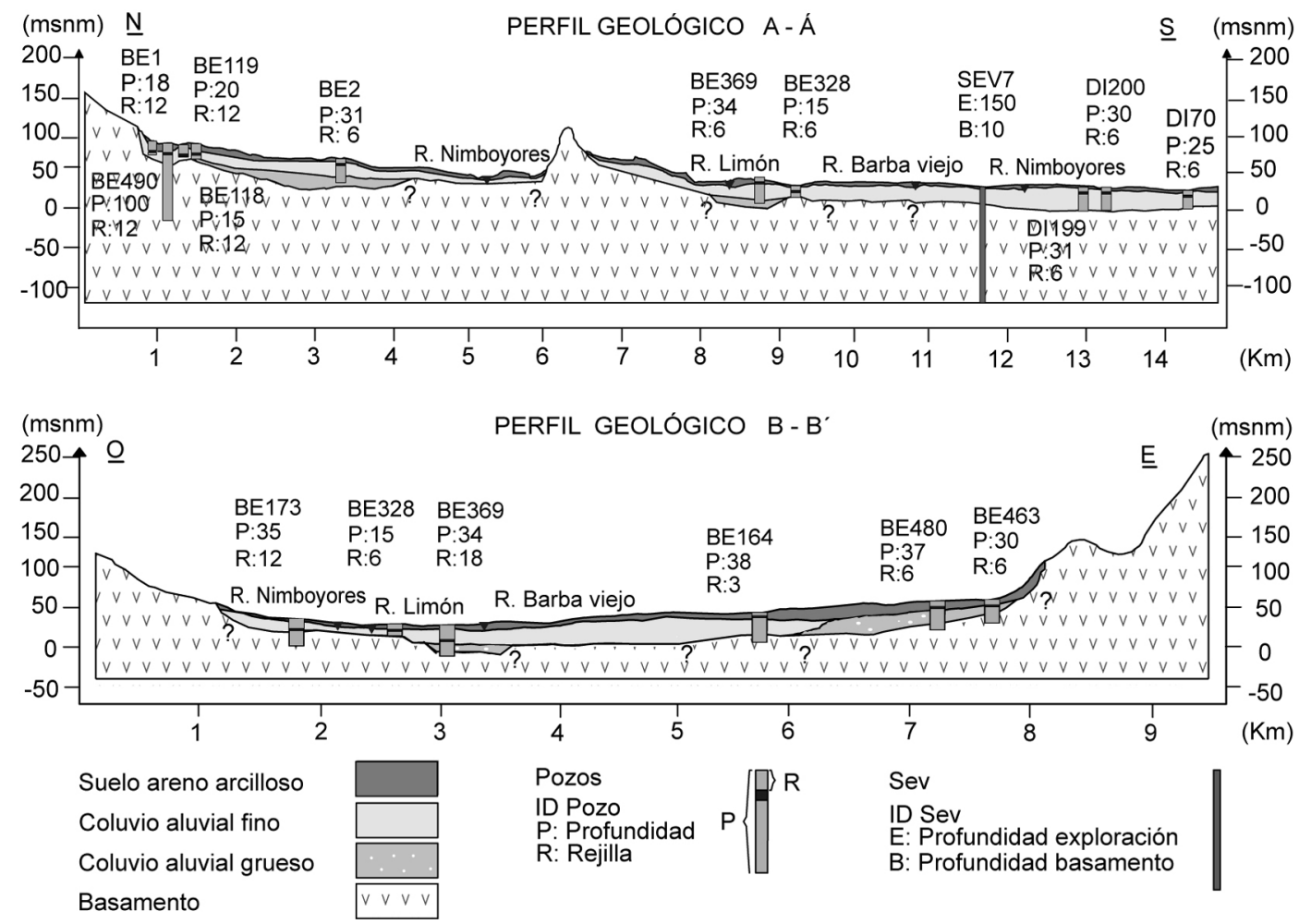

Fig. 5: Perfil geológico longitudinal A-Á y transversal B-B'.

para estos ríos representan un escurrimiento del almacenamiento de agua alojado en el depósito coluvio-aluvial, y que por coincidencias topográficas afloran en estos puntos, pasando el agua subterránea a transitar por los ríos. En el río Barba Viejo la naciente esta $4 \mathrm{~m}$ por debajo del nivel medio topográfico, lo que genera un encajonamiento del río. Desafortunadamente no hay pozos monitoreados por encima de esta naciente por lo que las curvas isofreáticas no son representativas. Sin embargo, con base en las condiciones geomorfológicas se estima que el acuífero aporta el flujo del agua subterránea a través del gradiente hidráulico, dando lugar a la naciente en el punto radialmente más bajo.
En este trabajo se investigaron las condiciones de influencia o efluencia del río respecto al acuífero y se analizaron los caudales registrados diferencialmente en el recorrido. Para ello se demarcaron los tramos donde se presentaba un cambio de comportamiento de caudal creciente o decreciente, registrando así los tramos donde el acuífero aporta agua al río, o el río aporta agua al acuífero (Fig. 12).

El acuífero deja de aportar agua al río conforme se va alejando de las zonas de recarga alojadas en los pie de monte a un nivel topográfico más alto que los ríos, cambiando a su condición opuesta en que el río aporta agua al acuífero en las partes planas de la cuenca, donde la velocidad del agua permite más permanencia e infiltración al medio poroso del acuífero. 


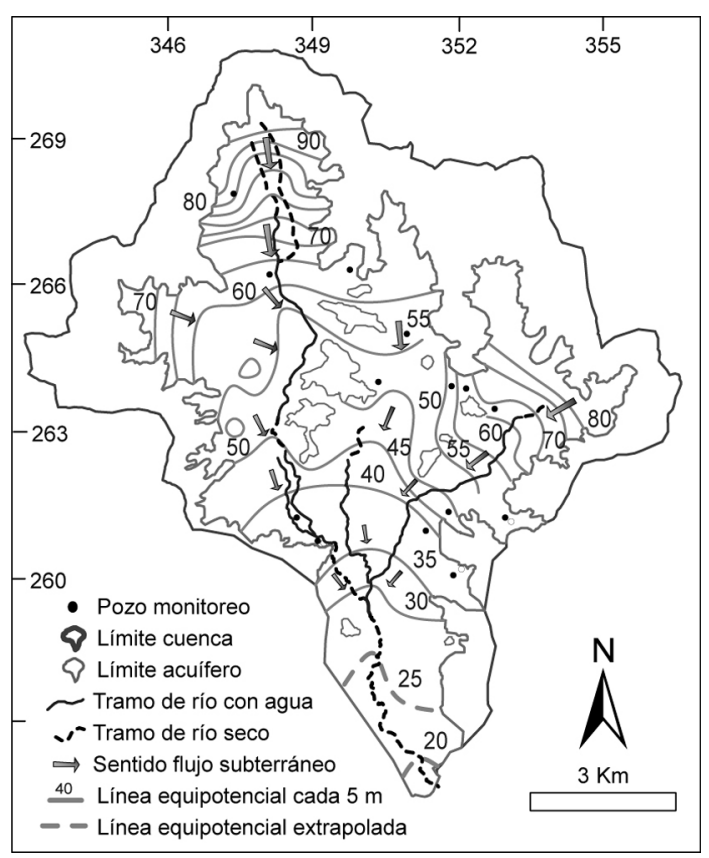

Fig. 6: Mapa de curvas isofreáticas elaborado con base en la información obtenida por medio de pozos de monitoreo (puntos negros).

\section{Balance de humedad de suelos - Cálculo de la recarga}

\section{Infiltración}

Se realizaron cuatro pruebas de infiltración con la finalidad de corroborar la información de estudios anteriores realizados por Ramos (2001), Burgos (2004) y Agudelo (2005) teniendo en consideración un total de 25 pruebas de infiltración (Cuadro 3).

\section{Clasificación de suelos}

El balance hídrico de suelos se realizó específicamente en la zona que corresponde a los depósitos coluviales, seguido en menor proporción por los gabros del intrusivo Potrero y los basaltos en el sector noroeste de las Unidades Esperanza y Matapalo respectivamente. Para ello se siguió la metodología propuesta por Schosinsky (2006). Fue indispensable determinar la precipitación mensual de la zona, los valores de infiltración básica de los suelos, la cobertura vegetal (uso del suelo), la pendiente, el coeficiente de infiltración, la densidad aparente de cada tipo de suelo, la profundidad de raíces de la cobertura vegetal, la capacidad de campo y el punto de marchitez.

La cuenca se subdividió en los 4 usos de suelos básicos (bosques, cultivos, pastos y zona urbana). No obstante, gracias a la información generada por las 25 pruebas de infiltración se se hizo posible elaborar una subclasificación de 11 tipos de suelos (Cuadro 4). Esta clasificación permitió la elaboración de 11 balances de humedad de suelo.

\section{Análisis de suelos}

En los puntos donde se efectuó cada prueba de infiltración, se extrajeron muestras de suelo, las cuales fueron debidamente empacadas y trasladadas al laboratorio de suelos del Instituto Nacional de Innovación y Transferencia en Tecnología Agropecuaria (INTA), con el fin de determinar la capacidad de campo, el punto de marchitez y la densidad aparente. Los resultados de los análisis realizados a las 15 muestras de suelo y las coordenadas de las 25 pruebas de infiltración realizadas se muestran en el cuadro 5.

Se determinaron 5 usos de suelo comprendidas por bosques, cultivo, pastos, pastos con arboles dispersos y urbano así como valores de infiltración en diferentes puntos (Fig. 13). La delimitación de cada una de estas regiones fue posible con el análisis de fotografías aéreas tomadas en el año 2007 a escala 1:25 000 generadas por el PRCR, esta información fue corroborada en campo en el año 2011. 


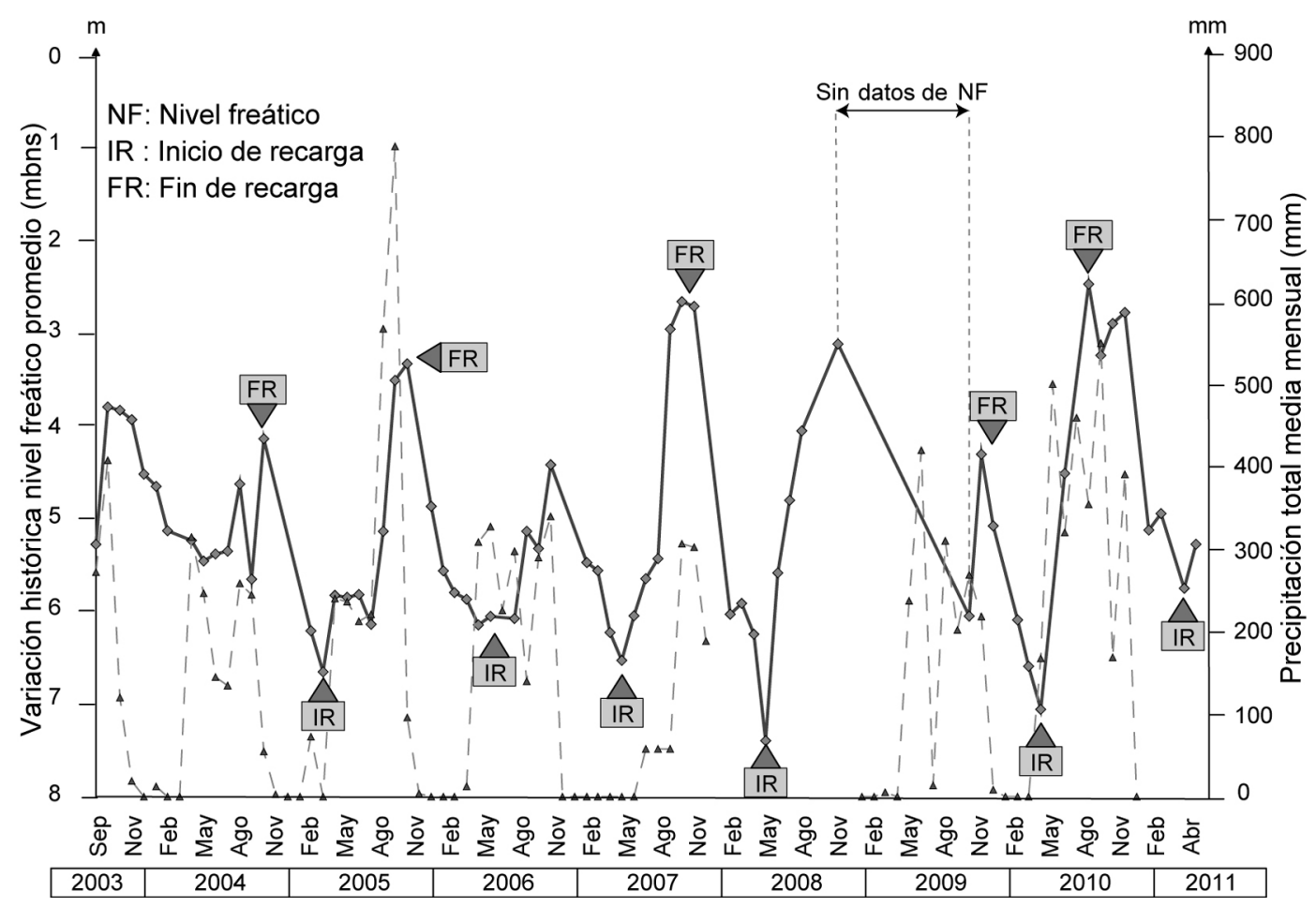

Fig. 7: Variación histórica el nivel estático promedio (línea continua) y de la precipitación media mensual.

En el cuadro 6 se muestran los resultados del volumen de recarga según el uso del suelo, de la cuenca. En función a los resultados obtenidos en cada zona de uso del suelo, la recarga total al acuífero, el producto de la precipitación y la evapotranspiración en la cuenca, es de $38,64 \mathrm{Mm}^{3} /$ año (millones de metros cúbicos por año); es decir, aproximadamente 1211 l/s.

\section{Modelo conceptual}

El modelo conceptual del acuífero ha sido elaborado de acuerdo con la información geológica, geofisica, límites permeables e impermeables y el marco hidrológico, los cuales están detallados a continuación:

\section{Marco geológico}

La cuenca está constituida por materiales recientes acarreados por la red hidrológica local y depósitos coluvio aluviales, los cuales son depositados en la zona baja y media de la cuenca, estos materiales según su granulometría son areno arcillosos en la parte superficial con espesores de $50 \mathrm{~cm}$ a $1 \mathrm{~m}$, seguido de arenas de grano grueso a fino conformando una capa oscilante entre 10 a $15 \mathrm{~m}$ y a profundidad existe una capa compuesta de gravas y cantos rodados con espesor entre los 15 a $20 \mathrm{~m}$, concentrados en zonas cerca a los cerros, además se encuentran afloramientos del basamento que conforman el límite de la cuenca y los cerros dentro de la planicie. 
Cuadro 4

Zonificación del área de estudio según infiltración y uso de suelo

\begin{tabular}{cccc}
\hline Zonas según uso de suelo & Área $\left(\mathrm{m}^{2}\right)$ & Velocidad de infiltración (mm/día) \\
\hline Zona urbana (ZU.1) & 1824312 & 3639 & Alta \\
Zona urbana (ZU.2) & 156231 & 789 & Media \\
Cultivos (ZC) & 2.983319 & 0,86 & Baja \\
Pastos (ZP.1) & 9303324 & 0,86 & Baja \\
Pastos con árboles dispersos (ZPA.1) & 10615326 & 2159 & Muy alta \\
Pastos con árboles dispersos (ZPA.2) & 3240545 & 1072 & Media \\
Pastos con árboles dispersos (ZPA.3) & 3970029 & 231 & Baja \\
Pastos con árboles dispersos (ZPA.4) & 16256375 & 72 & Alta \\
Bosques (ZB.1) & 21502002 & 3506 & Media \\
Bosques (ZB.2) & 25227520 & 38 & Baja \\
\hline B́rosques (ZB.3) & 8528464 & & \\
\hline
\end{tabular}

\section{Límites impermeables}

El límite impermeable lateral y en profundidad del acuífero está constituido por la unidad litoestratigráfica correspondiente a la unidad del Complejo Nicoya, conformada por gabros, doleritas y algunos plagiogranitos, se distribuye principalmente al norte de Tempate, así como al este y al oeste de la cuenca, cubriendo el cuerpo principal un área de $104 \mathrm{~km}^{2}$.

\section{Marco hidrológico}

El acuífero tiene como fuente de recarga las precipitaciones que ocurren según el régimen hidrológico de la cuenca durante los periodos lluviosos, la recarga ha sido calculada con base en el registro histórico de las estaciones meteorológicas de Cartagena, Potrero y Santa Cruz, siendo la intensidad de la precipitación media anual de 1986,7 mm/año. El modelo conceptual del acuífero es mostrado en las figura 14.

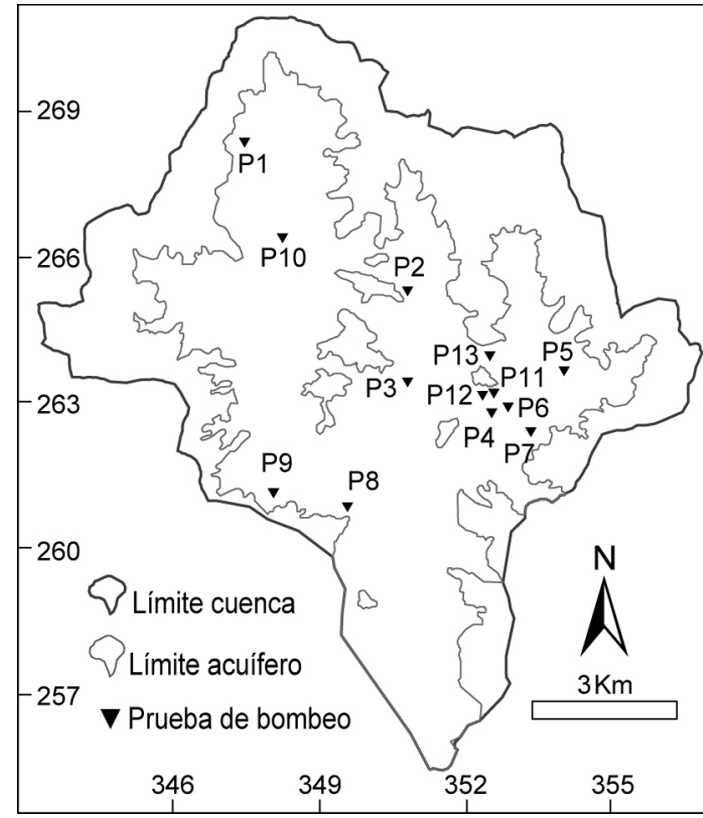

Fig. 8: Ubicación de pruebas de bombeo. 


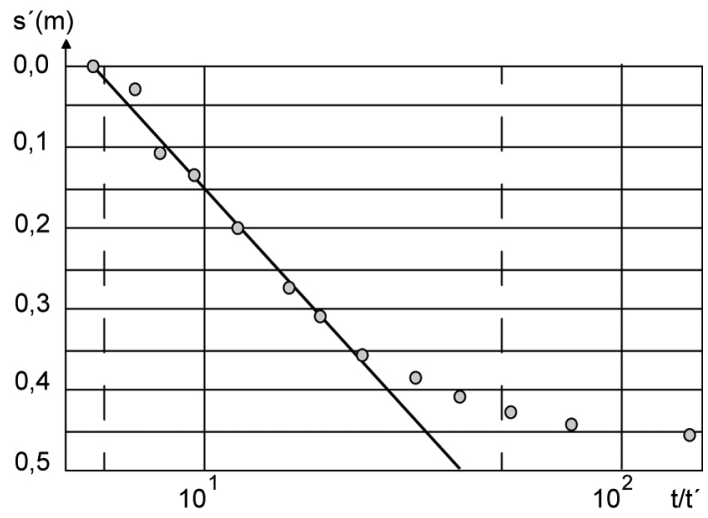

Fig. 9: Pozo P5, Análisis de la curva de recuperación por medio del método de Theis \& Jacob corregida.
Se determinó que el acuífero presenta una variación mínima de los niveles entre el periodo seco y lluvioso, con recuperación y conservación de su nivel estático, al completar el ciclo en mayo, el mes donde inicia la recarga, mostrando con ello que no existe sobre explotación del sistema.

Se localizaron los tramos de aporte de flujo del rio al acuífero, en las partes más planas de la cuenca en cercanías a la intersección de los ríos Barba Viejo, Limón y Nimboyores, y un aporte del acuífero a los ríos en las partes altas del acuífero donde nacen los ríos Barba Viejo y Nimboyores, por otra parte el rio Limón mantiene un patrón estable de aporte en toda la planicie.

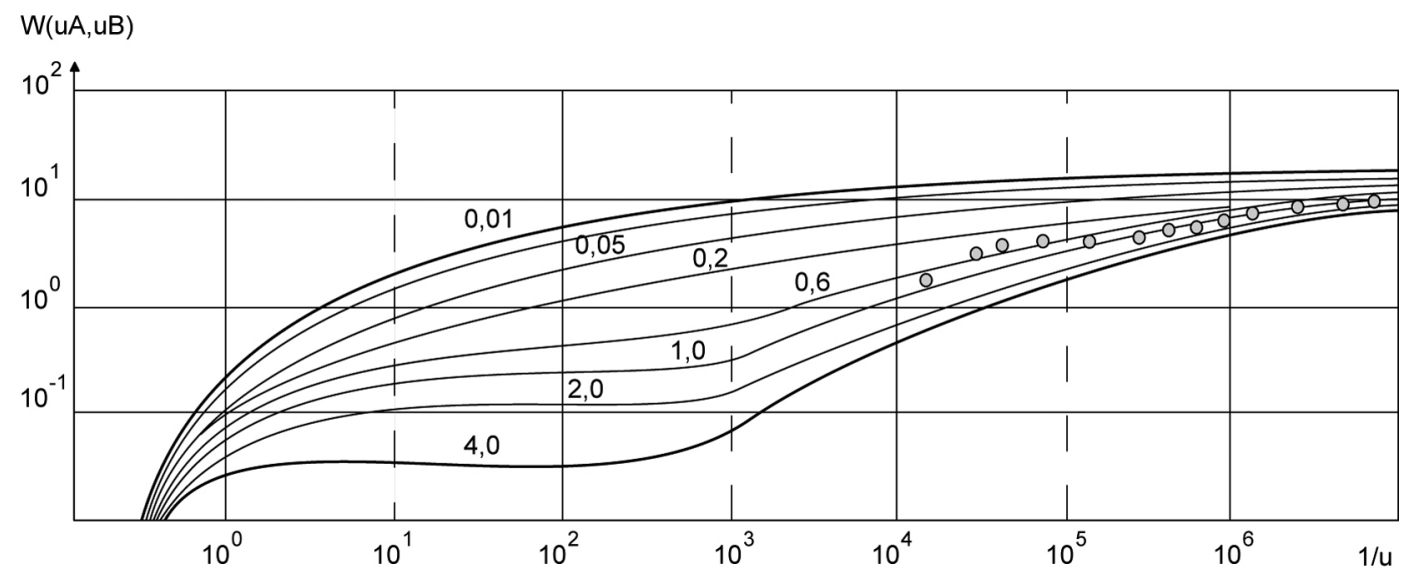

Fig. 10: Análisis de la curva de recuperación por el método de Newman para el pozo P6.

\section{CONCLUSIONES}

Se determinó que el acuífero del río Nimboyores es un acuífero libre y está constituido principalmente por depósitos coluvio aluviales. Asimismo el espacio saturado se divide en dos; el primero es una capa conformada por una matriz arcillosa limosa con arena de grano grueso a fino $\mathrm{y}$ arcillas grises, seguido a mayor profundidad de un coluvión medio a grueso, con arena, grava y cantos con poca arcilla. La profundidad media del basamento es $35 \mathrm{~m}$.

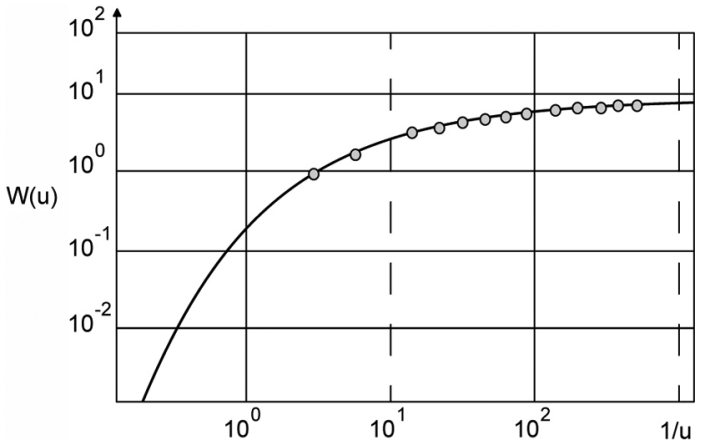

Fig. 11: Análisis de la curva de recuperación por el método de Theis Jacob corregida para el pozo P11. 


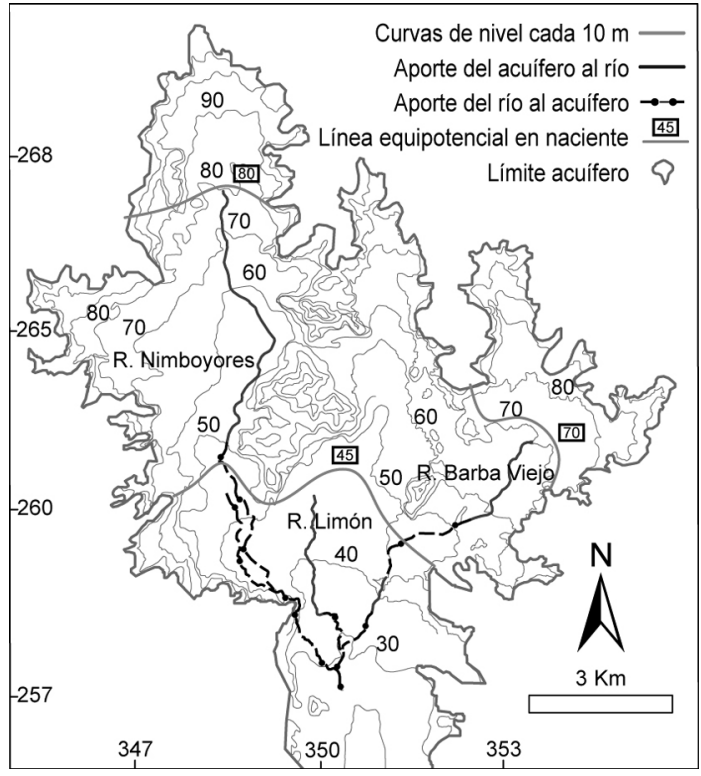

Fig. 12: Aforo diferencial en ríos, influencia y afluencia de los ríos. Basado en curvas de programa de regularización de catastro y registro (PRCR) del 2007.

El dominio del modelo del acuífero esta constituido en su perímetro y profundidad por la unidad del Complejo Nicoya, conformado por gabros, basaltos y radiolaritas. El basamento rocoso al NE se ubica a $35 \mathrm{~m}$ en el centro del valle. Conforme se desciende por la cuenca, se observa el relleno coluvio-aluvial, que aumenta en espesor, hallándose el basamento a $36 \mathrm{~m}$ y disminuyendo en sus laterales hasta $14,9 \mathrm{~m}$ por la derecha y $23,8 \mathrm{~m}$ por la izquierda. Finalmente a la salida el acuífero amplia su espesor, a una profundidad de 64,7 m. De este modo, en función al régimen hidrológico de la cuenca, y los límites del acuífero en estudio, se puedo elaborar el modelo conceptual del acuífero donde se consideraron 3 capas con espesores y cotas definidas como constituyentes del acuífero.

Se calculó una recarga total del acuífero de $38,6 \mathrm{Mm}^{3} /$ año; es decir $373 \mathrm{~mm} /$ año, Además se definieron conductividades hidráulicas de 10, 60 y $300 \mathrm{~m} / \mathrm{d}$ para el suelo areno arcilloso, coluvio fino y coluvio grueso respectivamente.

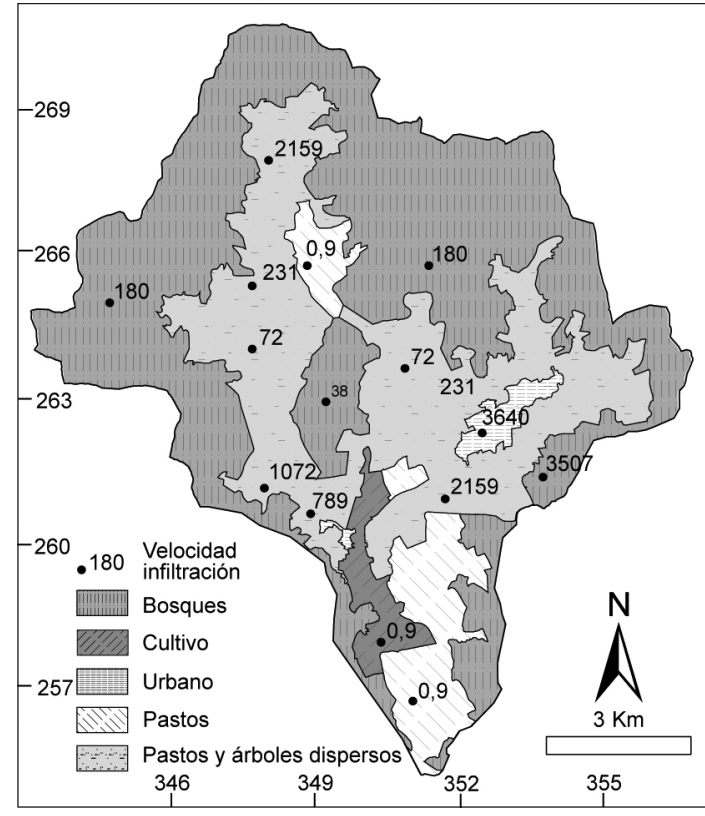

Fig. 13: Zonificación según uso de suelo y velocidad de infiltración.

\section{AGRADECIMIENTOS}

Se agradece al M.Sc. Federico Arellano Hartig, por el apoyo voluntario como director de la investigación, excelente guía y animosa constancia en el desarrollo del trabajo. A la M.Sc. Ingrid Vargas Azofeifa, por la cooperación como asesora en el desarrollo de los temas, y de su frecuente impulso para realizar la investigación. A la M.Sc. Clara Agudelo Arango, por la mediación en el suministro de información y en la coordinación de las pruebas de campo realizadas en representación de la Dirección de Gestión e Investigación de Aguas Subterráneas del SENARA. Al personal técnico del SENARA que apoyó la obtención de información de campo de la investigación, encabezado por el señor Rodolfo Arguedas León. La ayuda del geólogo Allan Alan fue de vital en las exploraciones geológicas y su interpretación. Al geólogo Wagner Valverde por su aporte en la geología regional del Complejo de Nicoya. Al geógrafo Jorge Suarez por la intervención oportuna en la 

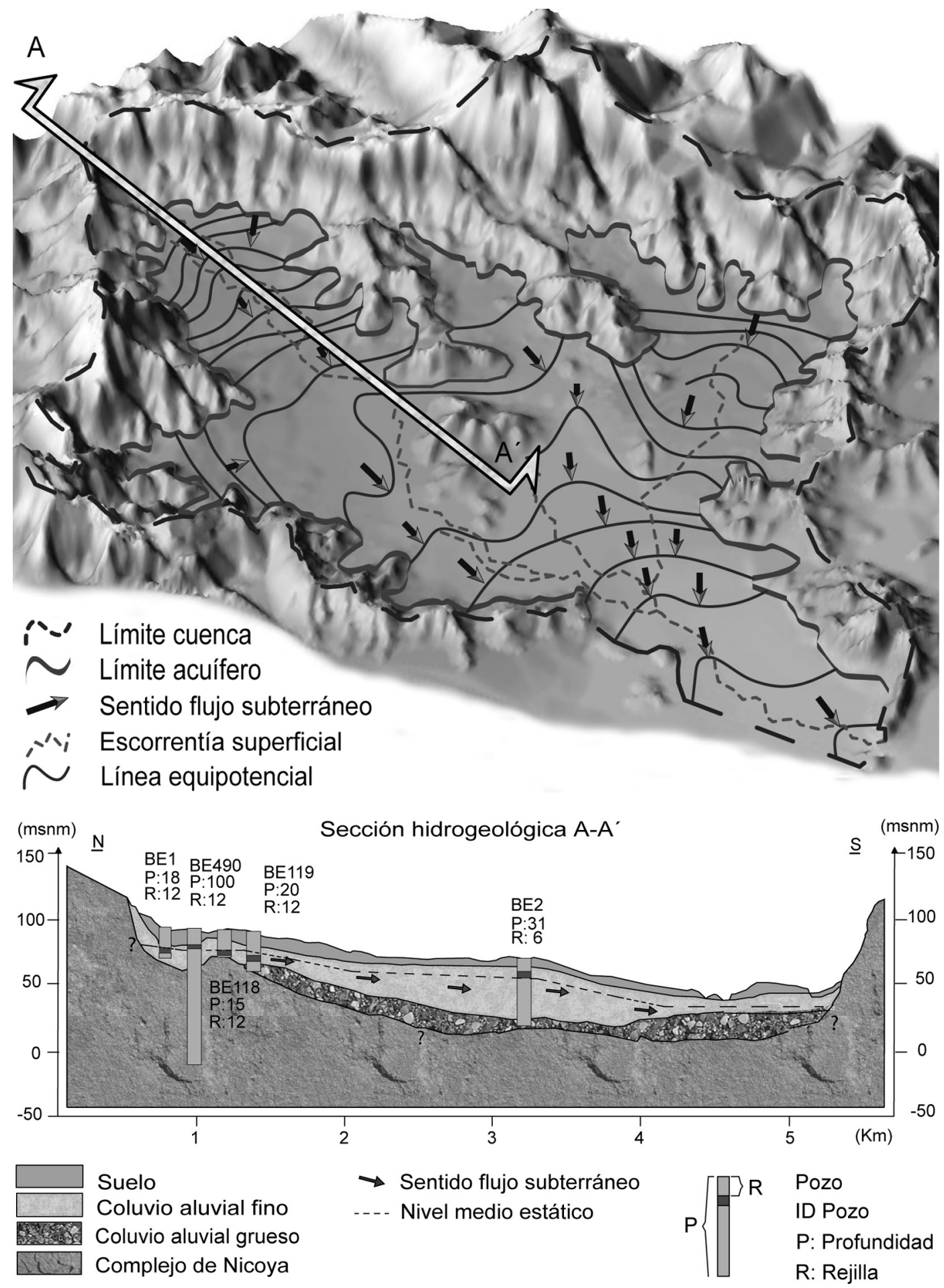

Fig.14: Modelo conceptual hidrogeológico del acuífero Nimboyores. 


\section{Cuadro 5}

Resultados de las pruebas de infiltración y análisis de suelos.

\begin{tabular}{|c|c|c|c|c|c|c|c|}
\hline Fuente & $\begin{array}{l}\mathrm{N}^{\circ} \text { de } \\
\text { prueba }\end{array}$ & Este & Norte & $\begin{array}{l}\text { Velocidad infiltración } \\
\qquad(\mathrm{cm} / \mathrm{min})\end{array}$ & $\begin{array}{c}\text { Capacidad } \\
\text { de campo } \\
(\%)\end{array}$ & $\begin{array}{l}\text { Punto de marchitez } \\
\qquad(\%)\end{array}$ & Uso suelo \\
\hline \multirow{3}{*}{ SENARA (TESIS) } & $\mathrm{S} 1$ & 348500 & 260600 & 0,0649 & 26,55 & 21,26 & ZPA \\
\hline & $\mathrm{S} 2$ & 347800 & 266000 & 0,0123 & 31,5 & 27 & ZPA \\
\hline & $\mathrm{S} 3$ & 352800 & 263150 & 0,0221 & 33 & 27 & ZPA \\
\hline \multirow{5}{*}{$\begin{array}{c}\text { infiltración } \\
\text { SENARA } 2004\end{array}$} & S4 & 347730 & 267469 & 0,1319 & 31,5 & 27 & ZPA \\
\hline & S5 & 351439 & 263619 & 0,0048 & 33 & 27 & $\mathrm{ZPA}$ \\
\hline & S6 & 352425 & 263475 & 0,0136 & 33 & 27 & $\mathrm{ZPA}$ \\
\hline & S7 & 352510 & 263545 & 0,2527 & 22 & 17 & $\mathrm{ZU}$ \\
\hline & S8 & 352630 & 263580 & 0,0081 & 22 & 17 & ZPA \\
\hline \multirow{8}{*}{ CATIE } & $\mathrm{C} 1$ & 347730 & 267969 & 0,1826 & 31,5 & 27 & $\mathrm{ZB}$ \\
\hline & $\mathrm{C} 2$ & 347707 & 267969 & 0,0083 & 31,5 & 27 & $\mathrm{ZB}$ \\
\hline & $\mathrm{C} 3$ & 352364 & 263375 & 0,0136 & 33 & 27 & $\mathrm{ZPA}$ \\
\hline & $\mathrm{C} 4$ & 352378 & 263605 & 0,3044 & 13,47 & 9,33 & $\mathrm{ZB}$ \\
\hline & $\mathrm{C} 5$ & 352370 & 263697 & 0,0089 & 13,47 & 9,33 & ZB \\
\hline & C6 & 349062 & 260503 & 0,0408 & 26,55 & 21,26 & $\mathrm{ZU}$ \\
\hline & $\mathrm{C} 7$ & 349059 & 260515 & 0,0689 & 26,55 & 21,26 & $\mathrm{ZU}$ \\
\hline & $\mathrm{C} 8$ & 349099 & 260585 & 0,0266 & 29,24 & 22,99 & ZPA \\
\hline \multirow{9}{*}{ AYA 2001} & A1 & 348600 & 266300 & 0,0001 & 31,5 & 27 & $\mathrm{ZP}$ \\
\hline & $\mathrm{A} 2$ & 347650 & 265850 & 0,006 & 31,5 & 27 & $\mathrm{ZPA}$ \\
\hline & A3 & 350150 & 266150 & 0,0026 & 29,07 & 22,45 & $\mathrm{ZB}$ \\
\hline & A4 & 350350 & 263300 & 0,084 & 33 & 27 & ZPA \\
\hline & A5 & 350400 & 261150 & 0,0001 & 45,83 & 32,68 & $\mathrm{ZC}$ \\
\hline & A6 & 350800 & 261350 & 0,0001 & 45,83 & 32,68 & $\mathrm{ZP}$ \\
\hline & A7 & 353800 & 263750 & 0,0042 & 35,93 & 32,95 & $\mathrm{ZPA}$ \\
\hline & A8 & 352300 & 262850 & 0,168 & 33 & 27 & $\mathrm{ZPA}$ \\
\hline & A9 & 347200 & 266400 & 0,0204 & 31,5 & 27 & ZB \\
\hline
\end{tabular}

Cuadro 6

Volumen de recarga por suelos - Acuífero Nimboyores

\begin{tabular}{lllll}
\hline $\begin{array}{l}\text { Uso del suelo \% Área en } \\
\text { cuenca }\end{array}$ & Retención & $\begin{array}{l}\text { Escorrentía } \\
\left(\mathrm{Mm}^{3} / \mathrm{año}\right)\end{array}$ & ETR & $\mathrm{Rp}$ \\
\hline Área urbana 2,2\% & 0,49 & 0,00 & 2,02 & 1,43 \\
Cultivos $2,5 \%$ & 0,73 & 3,11 & 2,07 & 0,01 \\
Pastos $38,2 \%$ & 1,06 & 18,45 & 40,59 & 16,53 \\
Bosques $57,1 \%$ & 22,15 & 10,88 & 56,08 & 20,67 \\
\hline Totales $\left(\mathrm{Mm}^{3} /\right.$ año) & 34 & 32,44 & 100,76 & 38,64 \\
$19 \%$ Precipitación anual /Recarga potencial 373 mm/año & & \\
\hline
\end{tabular}


digitalización de los mapas y presentación final. Al M.Sc. Mario Arias Salguero, director Centro de Investigaciones Geológicas de la Universidad de Costa Rica, por la promoción de esta investigación en el aporte del software Visual Modflow, en el préstamo de equipos de medición con que se realizó esta tesis, y su valiosa intervención en aporte de conocimiento. A la Municipalidad de Santa Cruz, por el apoyo del Departamento de Catastro y la oportuna y valiosa gestión de William Arauz Bran, jefe del Departamento Ambiental.A la comunidad de Lorena, encabezada por la Maestra María Rosa Angulo quien colaboró con las gestiones de ayuda de la comunidad en la logística de las actividades de campo realizadas.

\section{REFERENCIAS BIBLIOGRÁFICAS}

AGUDELO, C. \& PÉREZ, J., 2005: Diagnóstico del potencial de explotación y rendimiento seguro del acuífero en la parte alta de la subcuenca del río Nimboyores, Santa Cruz, Guanacaste.- 42 págs. SENARA. San José [Inf. interno].

ARAYA, J., 2008: AyA impulsa seis acueductos con fondos privados.- Semanario Universidad, sección País. Edición 583. Año XII.

BAUMGARTNER, P., 1984: El Complejo ofiolítico de Nicoya (Costa Rica): Modelos estructurales analizados en función de las edades de los Radiolarios (Calloviense a Santoniense).- En: SPECHMANN, P. (ed.): Manual de Geología de Costa Rica.320 págs. Ed. UCR, San José.

BAUMGARTNER, P.O. \& DENYER, P., 2006: Evidence for middle Cretaceous accretion at Santa Elena Peninsula (Santa Rosa Accretionary Complex), Costa Rica.- Geologica Acta, 4 (1-2): 179-191.

BURGOS, E., 2004: Plan Maestro Integral de la Microcuenca del río Nimboyores y su área de influencia Guanacaste, Costa Rica.270 págs. Centro Agronómico Tropical de Investigación y Enseñanza (CATIE), San José [Tesis M.Sc.].

CUSTODIO, E. \& LLAMAS, M.R., 1983: Hidrogeología Subterránea.- 2359 págs. Ed. Omega, Barcelona.

CHAVEZ, J., 1980: Aspectos geológicos de la cuenca del Río Nimboyores, Guanacaste.33 págs. Escuela de Geología UCR. San José, Costa Rica [Tesis Lic.].

DENYER, P. \& ARIAS, O., 1993: Geología del Norte de la Península de Nicoya, Costa Rica.- Rev. Geol. Amér. Central, 16: 69-84.

DENYER, P., MONTERO, W. \& FLORES, K., 2005: Apuntes sobre la geología de las hojas Golfo y Berrugate, Costa Rica.- Rev. Geol. Amér. Central, 32: 99-108. 
DENYER, P. \& BAUMGARTNER, P.O., 2006: Emplacement of Jurassic-Lower Cretaceous radiolarites of the Nicoya Complex (Costa Rica).- Geologica Acta, 4(1-2): 203-218.

DENYER, P., BAUMGARTNER, P.O. \& GAZEL, E., 2006: Characterization and tectonic implications of Mesozoic-Cenozoic oceanic assemblages of Costa Rica and Western Panamá.- Geologica Acta, 4(1-2): 219-235.

DENYER, P. \& GAZEL, E., 2009: The Costa Rican Jurassic to Miocene oceanic complexes: Orogin, tectonics and relations.-J. South Amer. Earth Sci. (28): 429-442.

KUIJPERS, E., 1979: La geología del Complejo ofiolítico de Nicoya, Costa Rica.- Inf. Sem. IGN, 1979(2): 15-75.

KUIJPERS, E.P. \& DENYER, P., 1979: Volcanic exhalative manganese deposits of the Nicoya Ophiolite Complex, Costa Rica.Econ. Geol. 74: 672-678.

PÉREZ, J., 2004: Monitoreo de aguas subterráneas en los acuíferos de la parte alta de la subcuenca del río Nimboyores - acuífero Nimboyores - y en la subcuenca de los ríos Matapalo y San Andrés - acuífero Huacas-Tamarindo.- 34 págs. SENARA, San José [Inf. interno].
RAMOS, V., 2001: Estudio hidrogeológico de la subcuenca del río Nimboyores.- 77 págs. AyA, San José [Inf. interno].

SCHOSINSKY, G., 2006: Cálculo de la recarga potencial de acuíferos mediante un balance hídrico de suelos.- Rev. Geol. Amér. Central, 34-35: 13-30.

SEGNINI, G., 2007: Dueño de Mapache controla agua en El Coco y Ocotal.- Periódico Nación. Publicado: 09 de marzo del 2007. http://wvw.nacion.com/ln_ee/2007/marzo/09/pais1020745.html. [Consulta: $10 \mathrm{de}$ agosto de 2011].

SINTON, C.W., DUNCAN, R.A. \& DENYER, P., 1997: Nicoya Peninsula, Costa Rica: A single suite of Caribbean oceanic plateau magmas.- J. Geoph. Res. 102(B7): 15,50715,520 .

TRIBUNAL CENTROAMERICANO DEL AGUA, 2004. Caso: Explotación del Acuífero de Nimboyores, Distritos de Cartagena, Tempate, Tamarindo, Cabo Velas; Cantón de Santa Cruz, Provincia de Guanacaste. Veredictos Segunda Audiencia Pública Llevada a cabo del 15 al 19 de marzo. San José, Costa Rica.http://www.tragua.com/audiencias/2004/ pdf_rdc/caso_acuifero_nimboyores.pdf. [Consulta: 10 de agosto de 2011]. 